less than 24 hours could not participate in the study. The use of other monoclonal antibodies and glucocorticoids for the treatment of COVID-19 were not allowed. Subjects were stratified according to the CRP level (CRP $\leq 7 \mathrm{mg} / \mathrm{L} ; \mathrm{CRP}>7 \mathrm{mg} / \mathrm{L}$ ) and then randomized (1:1) into 2 groups to receive LVL $324 \mathrm{mg}$ or placebo. LVL/ placebo were administered as a single subcutaneous injection, investigator and patients were unaware of the received therapy.

Among secondary endpoints of the study changes from baseline in ESR, CRP and IL-6 concentrations were assessed. CRP level and ESR were measured before the IP administration and on Days 3, 5, 7, 14, 21, 29 and 30. Blood samples for the measurement of IL- 6 concentration were obtained before the IP administration and then every day for 2 weeks after administration.

Results: We observed the pronounced decrease of ESR in LVL group compared to Placebo group. The difference was statistically significant on Days 3 and 7: the median ESR change from baseline was $-3 \mathrm{~mm} / \mathrm{h}$ and $+3 \mathrm{~mm} / \mathrm{h}$ on Day $3,-11 \mathrm{~mm} / \mathrm{h}$ and $-3.1 \mathrm{~mm} / \mathrm{h}$ on Day 7 , in LVL and Placebo groups, respectively $(p=0.0319$ and $p=0.0110$, Days 3 and 7$)$. The statistically significant difference in the change of CRP level was detected between the groups on Day 3: $-26.6 \pm 41.9 \mathrm{mg} / \mathrm{L}$ and $-19.2 \pm 58.2 \mathrm{mg} / \mathrm{L}$ in $\mathrm{LVL}$ and Placebo groups, respectively $(p=0.0241)$. Numerically the same dynamics of ESR and CRP was observed over entire study period.

The dynamics of IL-6 serum concentrations in LVL and Placebo groups was strikingly different. After LVL administration we detected the rapid significant increase in IL-6 concentration due to IL-6 receptors inhibition. Maximum change from baseline was observed on Day $3(+91.9 \pm 117.7 \mathrm{pg} / \mathrm{mL})$, on Day 14 the value was $+31.9 \pm 62.7 \mathrm{pg} / \mathrm{mL}$.

In the Placebo group, the IL-6 concentration increased slightly until Day 4 $(+5,1 \pm 76,5 \mathrm{pg} / \mathrm{mL})$, and then decreased significantly $(-39.2 \pm 55.1 \mathrm{pg} / \mathrm{mL}$ on Day 14) due to clinical improvement in this group.

Conclusion: The significant differences in the dynamics of ESR, CRP and IL-6 after LVL administration compared to placebo confirmed the pharmacodynamic effect and its potency to prevent the excessive release of inflammatory substances in severely ill COVID-19 patients.

REFERENCES:

[1] Xu X, Han M, Li T, Sun W, Wang D, Fu B, Zhou Y, Zheng X, Yang Y, Li X, Zhang X, Pan A, Wei H. Effective treatment of severe COVID-19 patients with tocilizumab. Proc Natl Acad Sci U S A. 2020 May 19;117(20):10970-10975. doi: 10.1073/pnas.2005615117. Epub 2020 Apr 29. PMID: 32350134; PMCID: PMC7245089.

Acknowledgements: We thank all contributors to the CORONA study

Disclosure of Interests: Nikita Lomakin: None declared, Bulat Bakirov: None declared, Gaziiavdibir Musaev: None declared, Denis Protsenko: None declared, Olga Moiseeva: None declared, Elena Pasechnik: None declared, Vladimir Popov: None declared, Elena Smolyarchuk: None declared, Ivan Gordeev: None declared, Michail Gilyarov: None declared, Daria Fomina: None declared, V Mazurov: None declared, Maria Morozova Employee of: JSC BIOCAD, Ekaterina Dokukina Employee of: JSC BIOCAD, Dmitrii Bogdan Employee of: JSC BIOCAD, Anton Lutskii Employee of: JSC BIOCAD, Arina Zinkina-Orihan Employee of: JSC BIOCAD, lulia Linkova Employee of: JSC BIOCAD, Anton Seleznev Employee of: JSC BIOCAD.

DOI: 10.1136/annrheumdis-2021-eular.2509

\section{POS1215 INFLUENCE OF CONFINEMENT CARRIED OUT BY PATIENTS WITH AUTOIMMUNE AND IMMUNE- MEDIATED INFLAMMATORY DISEASE WITH BIOLOGICAL TREATMENT ON COVID-19 INFECTION}

J. Font-Urgelles ${ }^{1}$, S. Mínguez ${ }^{1}$, B. Rodríguez-Diez ${ }^{1}$, L. Creus-Vila ${ }^{2}$, M. Esquius Rafat $^{2}$, X. Fusta Novell ${ }^{2}$, J. Llao Guardia ${ }^{3}$, E. Sainz Arnau ${ }^{3}$, M. Lopez de Recalde-Martorell ${ }^{1}$, A. Arnau Bartes ${ }^{4}$, M. Sallés Lizarzaburu ${ }^{1}{ }^{1}$ Althaia, Xarxa Assistencial Universitària de Manresa, Rheumatology, Manresa, Spain; ${ }^{2}$ Althaia, Xarxa Assistencial Universitària de Manresa, Dermatology, Manresa, Spain; ${ }^{3}$ Althaia, Xarxa Assistencial Universitària de Manresa, Gastroenterology, Manresa, Spain; ${ }^{4}$ Althaia, Xarxa Assistencial Universitària de Manresa, Research department, Manresa, Spain

Background: The disease caused by SARS-CoV-2 is a potentially serious infection. The autoimmune and immune-mediated inflammatory disease (AI/IMID) itself, its activity, the immunosuppression and the presence of comorbidities are associated with an increased risk of serious infections. At this moment the literature shows a similar risk of infection and severity compared to the general population. Some reports noted that these patients might adopt stricter measures of self-care protection than general population which could contribute to an incidence of infection lower than expected.

Objectives: To assess the incidence and clinical presentation of SARS-CoV-2 infection in our cohort of patients with AI/IMID treated with biological agents (BA) or Janus Kinasa (JAK) inhibitors. To analyse the association of the incidence and the type of confinement between the AI/IMID group and the general population.
Methods: A case-control study nested within a retrospective observational study was conducted from March $13^{\text {th }}$ until April $23^{\text {th }}, 2020$ in Althaia, Xarxa Assistencial Universitària de Manresa. Subjects: cohort of $\mathrm{Al} / \mathrm{IMID}$ patients followed by Rheumatology (inflammatory arthritis), Dermatology (psoriasis) and Digestology (inflammatory bowel disease) treated with BA/JAK inhibitors. Controls were selected from our Primary Care Centers. Main outcome: Type of confinement: strict: $<1$ outing / week with safety measures (SM), regular (2-3 outings with SM), lax (> 3 outings or face-to-face work with SM) and without confinement (without SM). Secondary outcome: SARS-CoV-2 infection: confirmed (PCR and/or positive serology), probable (severe illness requiring admission without PCR/serology or mild moderate with epidemiological contact) and possible (mild infection without microbiological check nor epidemiological contact); as well as severity according to the WHO

Results: 367 patients and 193 controls were included. $45.2 \%$ of patients were men, with a mean age of 52 (SD 14.6). 47.4\% were patients with rheumatologic disease, $25.3 \%$ from dermatology and $27.2 \%$ from digestive. $95.6 \%$ received a BA (66.6\% anti-TNF and $33.4 \%$ non-anti-TNF) and the remaining $4.4 \%$ received JAK inhibitors. $43.3 \%$ patients had at least a risk factor compared to $37.8 \%$ in the control group $(p=0.761)$. The Table 1 shows the incidence of COVID divided into confirmed and cumulative cases (confirmed and possible), with no significant differences. One patient $(0.3 \%)$ in the case group and 3 patients $(1.6 \%)$ in the control group required hospital admission $(p=0.121)$. In relation to the type of confinement we had significant differences $(p=0.013)$ within the AI/IMID group versus the control group in lax confinement. There were no differences in the incidence of COVID between the different confinement types.

\section{Table 1.}

\begin{tabular}{|c|c|c|c|c|}
\hline & Case $(n=367)$ & Control $(n=193)$ & $\mathrm{p}$-value & \\
\hline \multicolumn{5}{|l|}{ SARS-CoV-2 infection } \\
\hline Cumulative COVID & $10.1(7.2-13.6)$ & $13.5(9.0-19.1)$ & 0.228 & \\
\hline Confirmed COVID & $3.3(1.7-5.6)$ & $5.7(2.9-10.0)$ & 0.169 & \\
\hline Probable & $2.2(0.9-4.2)$ & $3.1(1.1-6.6)$ & 0.572 & \\
\hline Possible & $4.6(2.7-7.3)$ & $4.7(2.1-8.7)$ & 0.987 & \\
\hline Type of confinement & & & & OR (95\% Cl) \\
\hline Strict & $59.1(53.8-64.2)$ & $50.3(43.0-57.5)$ & 0.059 & $1.40(0.99-1.99)$ \\
\hline Regular & $15.4(11.8-19.5)$ & $14.4(9.9-203)$ & 0.813 & $1.06(0.65-1.73)$ \\
\hline Lax & $25.0(20.6-29.4)$ & 34.7 (28.0-41.9) & 0.013 & $0.62(0.42-0.91)$ \\
\hline No confinement & $0.5(0.1-1.9)$ & $0.5(0.01-0.03)$ & 1.000 & $1.05(0.09-11.7)$ \\
\hline
\end{tabular}

$\mathrm{Cl}$ : confidence interval; OR: Odds ratio

Conclusion: The incidence of COVID-19 infection in our cohort is similar to that reported in other series of AI/IMID patients and in general population, both for confirmed cases (3.3\% vs $5.7 \%$ ) as well as for cumulative cases $(10.1 \%$ vs $13.5 \%$ ). None of our patients developed a severe form of the infection. We observed that strict confinement was predominant in both groups, being higher in the $\mathrm{AI} / \mathrm{IMID}$ patients $(59.1 \%$ vs $50.3 \%$ ). Furthermore, lax confinement was more frequent in the control group. Although the difference was not statistically significant, the incidence of infection was higher in the control group, especially in the subjects who performed lax confinement.

Disclosure of Interests: None declared.

DOI: 10.1136/annrheumdis-2021-eular.2576

\section{POS1216 $\quad$ SYMPTOM RATES, ATTITUDES AND MEDICATION ADHERENCE OF RHEUMATIC AND MUSCULOSKELETAL DISEASE PATIENTS DURING THE SARS-CoV2 PANDEMIC}

K. Murray ${ }^{1}$, S. Quinn ${ }^{2}$, M. Turk ${ }^{1}$, A. O'rourke ${ }^{3}$, E. Molloy ${ }^{1}$, L. O'neill ${ }^{1}$, A. B. Mongey ${ }^{1}$, U. Fearon ${ }^{4}$, D. Veale ${ }^{1}$. ${ }^{1}$ Saint Vincent's University Hospital, Rheumatology, Dublin 4, Ireland; '2Saint Vincent's University Hospital, Radiology, Dublin, Ireland; '3St James' University Hospital, Infectious Diseases, Dublin, Ireland; ${ }^{4}$ Trinity College, Trinity Biomedical Sciences Institute, Dublin 2, Ireland

Background: SARS-CoV2 has caused over two million deaths globally. The relationship between rheumatic and musculoskeletal disease (RMDs), immunosuppressive medications and COVID-19 is unclear.

Objectives: This study explores the rates of COVID-19 symptoms and positive tests, DMARD adherence and attitudes to virtual clinics. amongst RMD patients.

Methods: An online population survey was disseminated via the Arthritis Ireland website and social media channels.

Results: There were 1381 respondents with RMD, $74.8 \%$ were on immunosuppressive medication. COVID-19 symptoms were reported by $3.7 \%$ of respondents of which $0.46 \%$ tested positive, no different from the general population at that timepoint. The frequency of COVID-19 symptoms was higher for respondents with spondyloarthropathy [odds ratio (OR) $2.06,95 \% \mathrm{Cl}: 1.14,3.70$ ] and lower in those on immunosuppressive medication (OR $0.48,95 \% \mathrm{Cl}: 0.27,0.88$ ), and 